Check for updates

Cite this: RSC Adv., 2019, 9, 28234

\title{
Intermediate band solar cell materials through the doping of group-VA elements (N, P, As and Sb) in $\mathrm{Cu}_{2} \mathrm{ZnSiSe}{ }_{4}$
}

\author{
Muhammad Jibran, ${ }^{a}$ Xia Sun, (D) *ab Bing Wang, ${ }^{a}$ Yasushi Yamauchi ${ }^{b}$ \\ and Zejun Ding (D)
}

\begin{abstract}
The electronic structure and optical properties of group-VA (N, P, As, and Sb)-doped $\mathrm{Cu}_{2} \mathrm{ZnSiSe}{ }_{4}$ alloys have been studied using a hybrid functional through density functional theory calculations. The minor lattice distortion and small formation energy indicate that synthesis of these alloys is highly possible in experiment. For each doped alloy, an isolated and partially filled intermediate band (IB) appears in its band structure. The doping-induced IB is mainly contributed by the s states of the doped group-VA atom and the $p$ states of four neighboring Se atoms, and slightly by the $\mathrm{d}$ states of eight $\mathrm{Cu}$ atoms. The existence of an IB obviously enhances the absorption coefficient with two additional absorption peaks in the visible light range. For $\mathrm{P}, \mathrm{As}$ and $\mathrm{Sb}$-doped $\mathrm{Cu}_{2} \mathrm{ZnSiSe}_{4}$ alloys, not only the bandgap between the valence band maximum and the conduction band minimum but also the sub bandgap between the valence band maximum and the IB are very close to the optimal values for visible light absorption. Therefore, these alloys are recommended as good candidates for IB solar cell materials.
\end{abstract}

Received 10th August 2019

Accepted 30th August 2019

DOI: 10.1039/c9ra06236j

rsc.li/rsc-advances due to its appropriate bandgap $(2.43 \mathrm{eV}) .{ }^{12}$ The IBs are predicted to be formed by doping of 3d-metal atoms such as $\mathrm{Ti}^{11,13} \mathrm{Cr},{ }^{10,11}$ $\mathrm{Fe}^{\mathbf{8 , 1 4}}$ and $\mathrm{Ni}^{8}$ in $\mathrm{CuGaS}_{2}$. The shortcomings of the IBs induced by doping of $\mathrm{Ti}, \mathrm{Fe}$ and $\mathrm{Ni}$ in $\mathrm{CuGaS}_{2}$ are occupied or unoccupied based on relatively accurate hybrid functionals, ${ }^{\mathbf{8}, 15}$ but not partially filled states which are expected in practical applications. Furthermore, Yang et al. proposed that transition metals might not be the best dopant to fabricate IBSCs. ${ }^{\mathbf{1 6}}$ The localized $3 \mathrm{~d}$ states of transition metals may result in low light absorption coefficient and low carrier mobility. ${ }^{\mathbf{1 6}}$ Elements from group-IV and VA as dopants create delocalized s states which could be more appropriate to enhance the parameters. ${ }^{16-19}$ For the host of $\mathrm{Cu}_{2} \mathrm{ZnSnS}_{4}$, the doping of $\mathrm{Sb}$ at $\mathrm{Sn}$ site has the lowest formation energy than other sites such as $\mathrm{Cu}, \mathrm{Zn}$ and $\mathrm{S} .{ }^{\mathbf{1 7}}$ By using more accurate hybrid functional instead of the generalized gradient approximation (GGA), it is predicted that partially filled IBs can form in Sn-doped $\mathrm{CuInS}_{2}$ and $\mathrm{CuGaS}_{2}{ }^{16}$ (P, As, Sb)-codoped $\mathrm{CuGaS}_{2}$ at $\mathrm{Ga}$ and S sites, ${ }^{19}$ (Si, Ge, Sn)-doped $\operatorname{AgAlTe}_{2}{ }^{18}$ and Sb-doped $\mathrm{Cu}_{2} \mathrm{ZnSnS}_{4}{ }^{17}$ Whereas, the use of toxic or costly elements, like $\mathrm{Ga}, \mathrm{Ag}$, Te or In, in the host materials is highly demanded to be replaced by nontoxic and cheap elements.

In this paper, the $\mathrm{Cu}_{2} \mathrm{ZnSiSe}_{4}$ alloy is chosen as host material, whose bandgap $(2.33 \mathrm{eV})^{20}$ is very close to the ideal value $(2.41 \mathrm{eV})$ for IBSCs. ${ }^{5}$ The group-VA elements (N, P, As, and Sb) are selected as dopants to replace $\mathrm{Si}$ atom in order to easily form n-type semiconductor. The delocalized s states of group-VA elements will help to form delocalized IBs and generate freely transported carriers. Our calculation shows that an isolated and partially filled IB is induced in all the four doped alloys. The IB 
is dominated by the hybridization of M-s and Se-p states as well as slightly contributed by $\mathrm{Cu}-\mathrm{d}$ states. Compared with that of the host material, absorption coefficient of group-VA doped $\mathrm{Cu}_{2} \mathrm{ZnSiSe}_{4}$ is largely enhanced with additional two peaks in the visible light range.

\section{Computational details}

All calculations are performed with in the density functional theory (DFT) using Vienna $A b$ initio Simulation Package (VASP) ${ }^{21,22}$ with the projector augmented wave (PAW) method. ${ }^{23}$ The plane-wave energy cutoff is set to $400 \mathrm{eV}$. Our previous study has revealed that the total energy of $\mathrm{Cu}_{2} \mathrm{ZnSiSe}_{4}$ in kesterite (KS) structure (Fig. 1a) is lower than those in stannite and wurtzitestannite structures through both GGA and hybrid functional calculations. ${ }^{24}$ Experimentally, $\mathrm{Cu}_{2} \mathrm{ZnSiSe}_{4}$ and $\mathrm{Cu}_{2} \mathrm{ZnSiS}_{4}$ are observed in wurtzite-stannite structure ${ }^{25,26}$ but $\mathrm{Cu}_{2} \mathrm{ZnGeSe}_{4}$ in KS structure. ${ }^{27}$ Here, a $2 \times 2 \times 1$ supercell of KS structure is used which includes 64 atoms. One $\mathrm{Si}$ atom is replaced by one group-VA atom $\mathbf{M}(\mathbf{M}=\mathrm{N}, \mathrm{P}, \mathrm{As}$ and $\mathrm{Sb})$ in this supercell. Correspondingly, the dopant concentration is $12.5 \%$. A $4 \times 4 \times$ $4 k$-point mesh is applied using Monkhorst-Pack method in all calculations. ${ }^{28}$ Structural optimizations are performed by GGA with the Perdew-Burke-Ernzerhof (PBE) form. ${ }^{29}$ The band structure and optical property are calculated through hybrid functional, which is known to be more accurate than GGA in prediction of electronic property of semiconductors. However, the calculated bandgap of $\mathrm{Cu}_{2} \mathrm{ZnSiSe}_{4}$ is $1.76 \mathrm{eV}$ through standard HSE06, ${ }^{30}$ which is obviously still smaller than the experimental value $(2.33 \mathrm{eV}) .^{20}$ The bandgap depends on the mixing parameter $\alpha$, which defines the fraction of exact exchange and is set as 0.25 in HSE06. ${ }^{30}$ When the value of $\alpha$ is adjusted to 0.35 , the corresponding bandgap is increased to $2.26 \mathrm{eV}$, which is much closer to the experimental value. The adjustment of $\alpha$ is also adopted in the calculation of $\mathrm{Cu}_{2} \mathrm{ZnSnS}_{4}$ (ref. 17) and
$\mathrm{Cu}_{2} \mathrm{Cd}_{x} \mathrm{Zn}_{1-x} \mathrm{SnS}_{4} \cdot{ }^{31}$ In this study, all calculations have used an increased $\alpha$ value (0.35).

\section{Results and discussion}

Our calculations show that the lattice constants ( $a$ and $c$ ) decrease in the presence of the $\mathrm{N}$ substitution and increase in the presence of the $\mathrm{P}$, As and $\mathrm{Sb}$ substitutions (Fig. 1a and $\mathrm{b}$ ). For the P-doped alloy, the lattice variation is only $0.16 \%$ due to atomic radii of the doped $\mathrm{P}$ element close to the one of $\mathrm{Si}$ element. Even for the elements with larger atomic number (As, $\mathrm{Sb}$ ), the lattice variations are less than $0.6 \%$, indicating that the lattice distortion is minor. Such minor lattice distortion is quite favorable to the synthesis of doped alloys. Actually, primary change occurs at the local geometry around dopant. The bond length of $\mathrm{Si}-\mathrm{Se}$ in the host $\mathrm{Cu}_{2} \mathrm{ZnSiSe}_{4}$ is $2.337 \AA$. After the substitution of one $\mathrm{Si}$ atom by one group-VA atom $\mathrm{M}$, the bond lengths of $\mathrm{M}-\mathrm{Se}(\mathrm{M}=\mathrm{N}, \mathrm{P}, \mathrm{As}$ and $\mathrm{Sb})$ are 2.199, 2.438, 2.543 and $2.683 \AA$, respectively. In accordance with atomic radii, the variation is smallest by the doping of $\mathrm{P}$ and largest by that of $\mathrm{Sb}$. To evaluate the miscibility of group-VA doped $\mathrm{Cu}_{2} \mathrm{ZnSiSe}_{4}$ alloys, the formation enthalpy $\Delta H(\mathrm{M})$ is defined and calculated as:

$\Delta H(\mathrm{M})=E_{\mathrm{Cu}_{2} \mathrm{ZnSi}_{0.875} \mathrm{M}_{0.125} \mathrm{Se}_{4}}-0.875 E_{\mathrm{Cu}_{2} \mathrm{ZnSiSe}_{4}}-0.125 E_{\mathrm{Cu}_{2} \mathrm{ZnMSe}_{4}}$

where $E_{\mathrm{Cu}_{2} \mathrm{ZnSi}_{0.875} \mathrm{M}_{0.125} \mathrm{Se}_{4}}, E_{\mathrm{Cu}_{2} \mathrm{ZnSiSe}_{4}}$ and $E_{\mathrm{Cu}_{2} \mathrm{ZnMSe}_{4}}$ are the total energies of $\mathrm{Cu}_{2} \mathrm{ZnSi}_{0.875} \mathrm{M}_{0.125} \mathrm{Se}_{4}, \mathrm{Cu}_{2} \mathrm{ZnSiSe}_{4}$ and $\mathrm{Cu}_{2} \mathrm{ZnMSe}_{4}$ alloys, respectively. In consistence with the lattice distortion, formation enthalpy is smallest for the doping of $\mathrm{P}$ (2.69 meV per atom) and largest for the doping of $\mathrm{Sb}(6.01 \mathrm{meV}$ per atom) (Fig. 1c).These formation enthalpies are smaller than that of currently commercialized solar cell material $\mathrm{Cu}\left(\mathrm{In}_{0.5} \mathrm{Ga}_{0.5}\right)$ $\mathrm{Se}_{2}\left(11 \mathrm{meV}\right.$ per atom), ${ }^{32}$ and comparable to that of IBSC $\mathrm{Ag}(\mathrm{Al}, \mathrm{Sn}) \mathrm{Te}_{2}(3.75 \mathrm{meV}$ per atom $),{ }^{18}$ and those of same host $\mathrm{Cu}_{2} \mathrm{Zn}\left(\mathrm{Si}_{0.25} \quad \mathrm{Sn}_{0.75}\right) \mathrm{Se}_{4} \quad(2.8 \mathrm{meV} \text { per atom })^{33}$ and

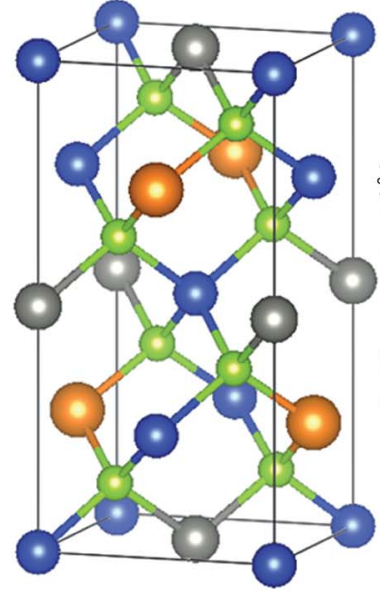

(a)

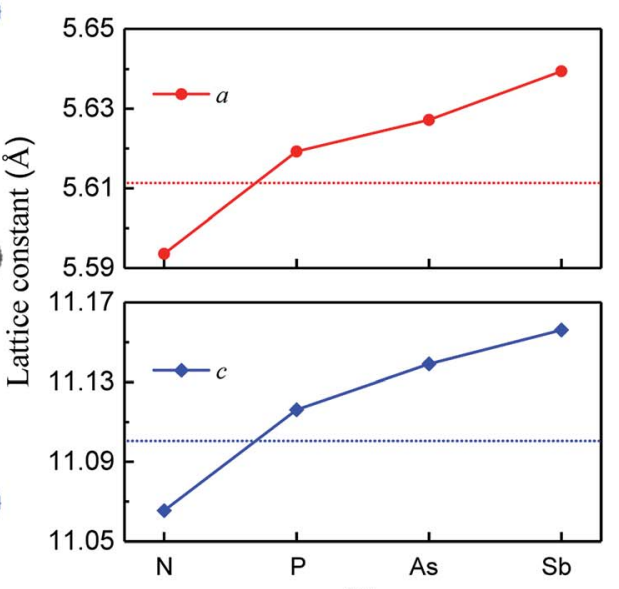

(b)

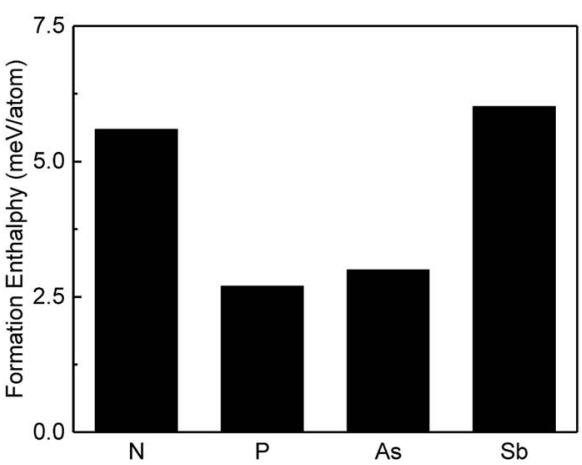

(c)

Fig. 1 (a) Crystal structure of $\mathrm{Cu}_{2} \mathrm{ZnSiSe}_{4}$ in kesterite (KS) phase. The $\mathrm{Cu}, \mathrm{Zn}, \mathrm{Si}$, and Se atoms are represented by blue, grey, orange and green spheres, respectively. (b) The calculated lattice constants. (c) Formation enthalpy of group-VA doped $\mathrm{Cu}_{2} \mathrm{ZnSi}_{0.875} \mathrm{M}_{0.125} \mathrm{Se}_{4}(\mathrm{M}=\mathrm{N}, \mathrm{P}, \mathrm{As}$ and $\mathrm{Sb}$ ) alloys. 
$\mathrm{Cu}_{2} \mathrm{ZnSn}\left(\mathrm{S}_{0.75} \mathrm{Se}_{0.25}\right)_{4}(5.0 \mathrm{meV}$ per atom $),{ }^{34}$ indicating that synthesis of group-VA doped $\mathrm{Cu}_{2} \mathrm{ZnSiSe}_{4}$ alloys are highly possible in experiment.

Band structures of the host and doped alloys are shown in Fig. 2a. The calculated bandgap of $\mathrm{Cu}_{2} \mathrm{ZnSiSe}_{4}(2.26 \mathrm{eV})$ agrees well with the experimental value $(2.33 \mathrm{eV}) .{ }^{20}$ Energy interval of $0.40 \mathrm{eV}$ between the VBM and the Fermi level $\left(E_{\mathrm{F}}\right)$ is smaller than that value of $1.86 \mathrm{eV}$ between the $E_{\mathrm{F}}$ and the CBM. After the doping of group-VA atom $\mathrm{M}(\mathrm{M}=\mathrm{N}, \mathrm{P}, \mathrm{As}$ and $\mathrm{Sb})$, the bandgaps between CBM and VBM ( $\left.\Delta_{\mathrm{CBM}-\mathrm{VBM}}\right)$ are among $2.21-2.39 \mathrm{eV}$, close to that of host (Fig. 2b). The most significant variation in band structure is the introduction of IB. For all the four doped cases, IBs are isolated and partially filled. This is exactly what IBSCs need to ensure the three-photon absorption processes. As indicated in Fig. 2a, IBs introduced by these four dopants have similar shapes, but positions of the band edges (CBM and VBM) show dependence on the specific dopants. Fig. 2b shows the bandgap and two sub bandgaps of doped alloys, one is between the CBM and IB at the $\Gamma$ point $\left(\Delta_{1}\right.$ CBM-IB $)$ and the other is between the IB and VBM at the $\Gamma \operatorname{point}\left(\Delta_{2}\right.$ IB-VBM $)$. It is noticed that shapes of the edges of VBM and CBM have no big difference among four doped alloys. The N-doped alloy has the largest $\Delta_{1}$
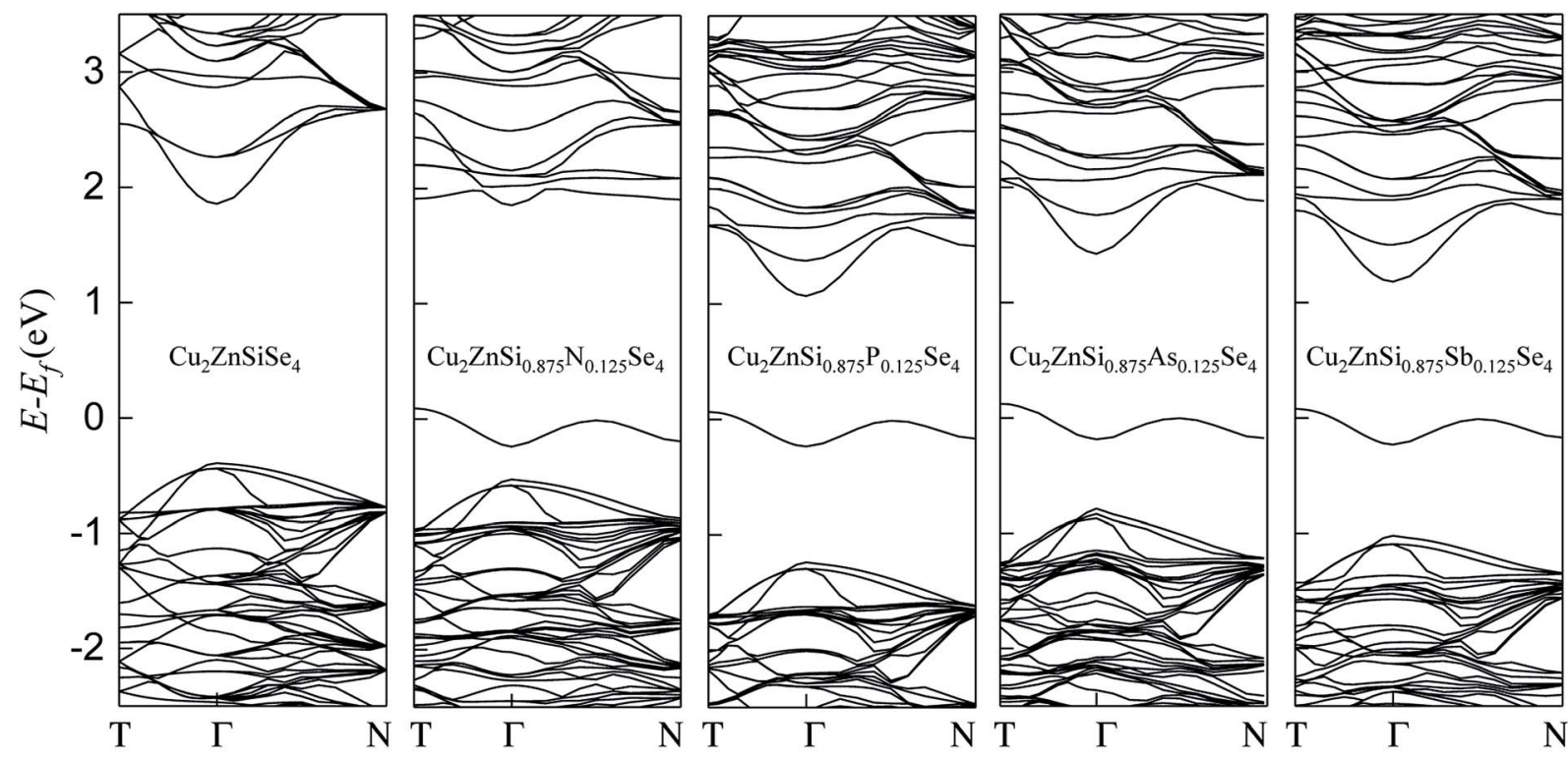

(a)

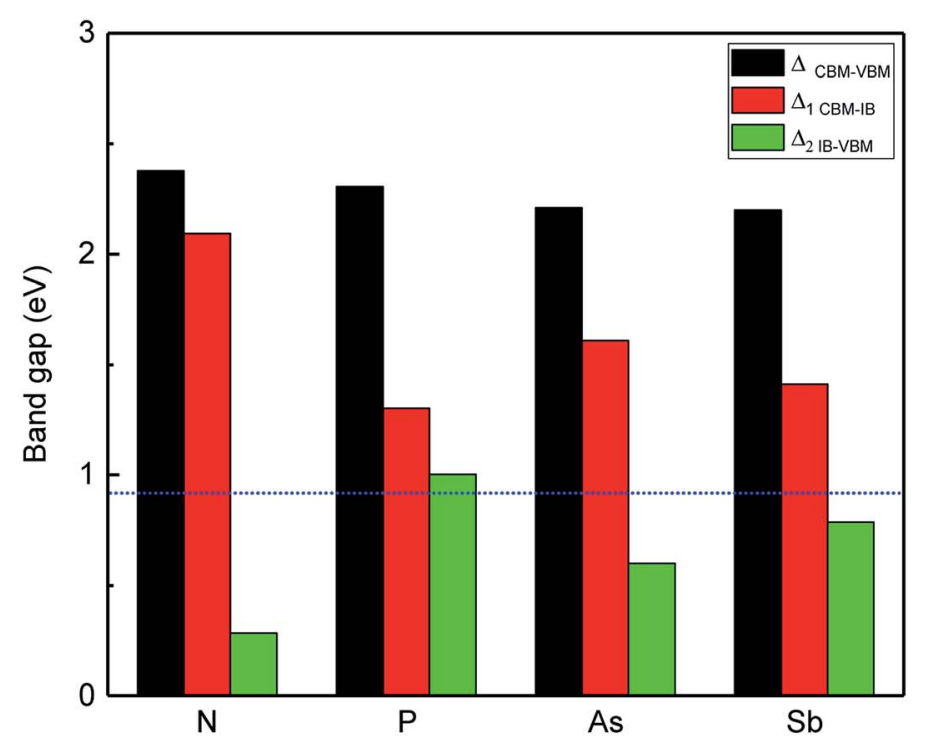

(b)

Fig. 2 (a) The band structures of host material $\left(\mathrm{Cu}_{2} \mathrm{ZnSiSe}\right.$ ) and group-VA doped alloys $\mathrm{Cu}_{2} \mathrm{ZnSi}_{0.875} \mathrm{M}_{0.125} \mathrm{Se}_{4}(\mathrm{M}=\mathrm{N}, \mathrm{P}, \mathrm{As}$ and $\mathrm{Sb})$. Fermi level of each alloy is set to zero (b) the bandgap between CBM and VBM, and two sub bandgaps between CBM and IB, IB and VBM, respectively. The dotted line represents the optimal value of sub bandgap for IBSCs. 
Свм-Ів $(2.09 \mathrm{eV})$ and the smallest $\Delta_{2 \text { IB-VBM }}(0.29 \mathrm{eV})$. In contrast,

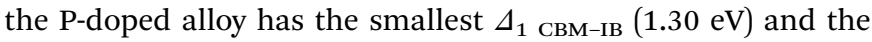
largest $\Delta_{2}$ Ів-Vвм $(1.00 \mathrm{eV})$, which will be discussed later.

Fig. 3a and $\mathrm{b}$ show the total DOS and projected DOS (PDOS) of group-VA doped $\mathrm{Cu}_{2} \mathrm{ZnSiSe}_{4}$ alloys. The VBM are mainly composed by $\mathrm{Cu}-3 \mathrm{~d}$ and Se-4p states (Fig. $3 \mathrm{~b}$ ), same as the host material. As to the conduction band, a prominent peak locates at about $2.0 \mathrm{eV}$. Beside the Se- $4 \mathrm{p}$ and Si-3s states, there is obvious contribution from the $\mathrm{p}$ states of doped elements $\mathrm{M}$ (M $=\mathrm{N}, \mathrm{P}, \mathrm{As}$ and $\mathrm{Sb}$ ) to this peak. Fig. 3c plots the isosurface of the band-decomposed charge density of IB for the P-doped alloy. IB charge density is contributed dominantly by one doping atom (P) and four neighboring Se atoms, as well as slightly by eight adjacent $\mathrm{Cu}$ atoms in the supercell. Similarly, the IBs of other three doped alloys are also primarily composed by the antibonding states of M-s and Se-4p. The atomic orbital energies of N-2s, P-3s, As-4s and Sb-5s are $-18.58,-13.97,-14.49$ and $-12.83 \mathrm{eV}$, respectively. Since the atomic orbital energy of N-2s is much lower than the other three, the corresponding IB formed by the anti-bonding hybridization of N-2s and Se- $4 \mathrm{p}$ is at the lowest position and closest to the VBM, resulting in the smallest $\Delta_{2}$ Iв-VBM. Besides the atomic orbital energy, interactions between doped elements and Se atoms are influenced by their bond lengths. Although atomic orbital energy of P-3s $(-13.97 \mathrm{eV})$ is lower than that of $\mathrm{Sb}-5 \mathrm{~s}(-12.83 \mathrm{eV})$, the bond length of P-Se (2.438 $\AA$ ) is smaller than that of As-Se (2.683 $⿱$ ). The anti-bonding state by P-3s and Se- $4 \mathrm{p}$ is pushed to a higher energy than that by Sb-4s and Se-4p. Therefore, the IB of Pdoped alloy stays at the highest position among four antibonding states and has the largest value of $\Delta_{2}$ IB-VBM, as indicated in Fig. 2b.

Fig. 4 compares optical absorption coefficients $\alpha(\omega)$ of groupVA doped alloys with that of the host material. Solar spectrum is also shown in the background. It can be seen that the difference of $\alpha(\omega)$ in the $z z$ and $x x$ directions (parallel to the $c$ and $a$ axis, respectively) is insignificant. For the host of $\mathrm{Cu}_{2} \mathrm{ZnSiSe}_{4}$ (blue lines in Fig. 4), there is only one absorption peak $(2.62 \mathrm{eV})$ at the main solar light energy range, which corresponds to the electron transition from the VB to the CB. Furthermore, absorption coefficient is considerably small when the photon energy is

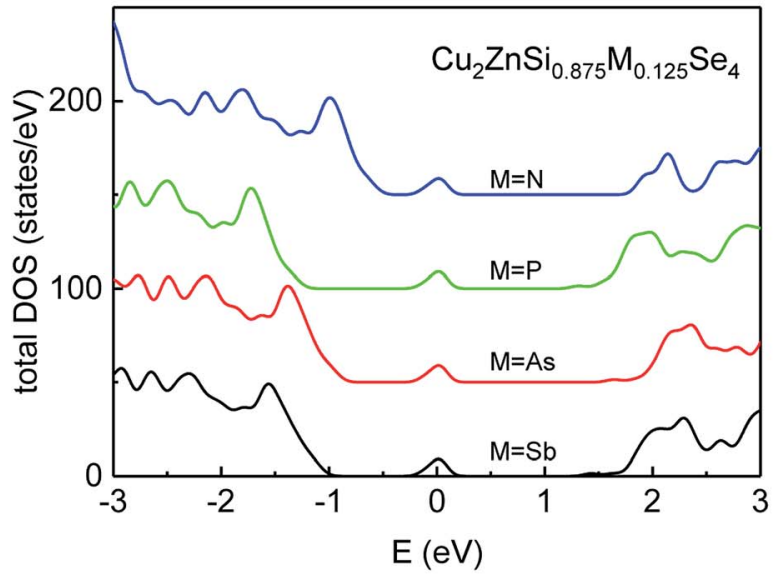

(a)

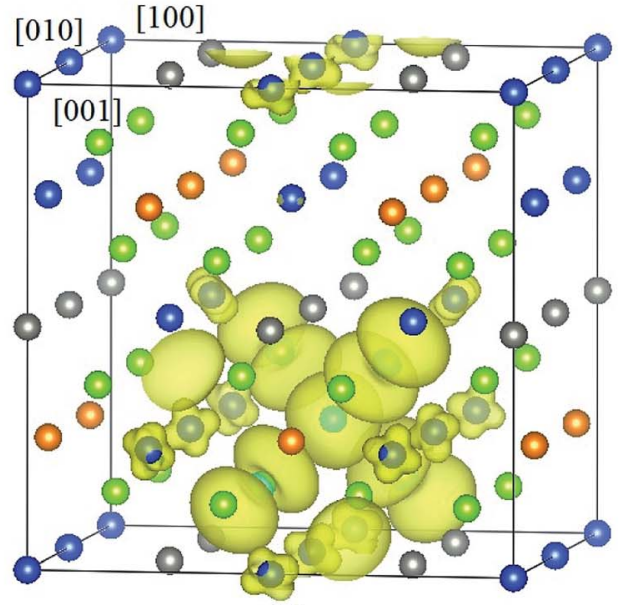

(c)

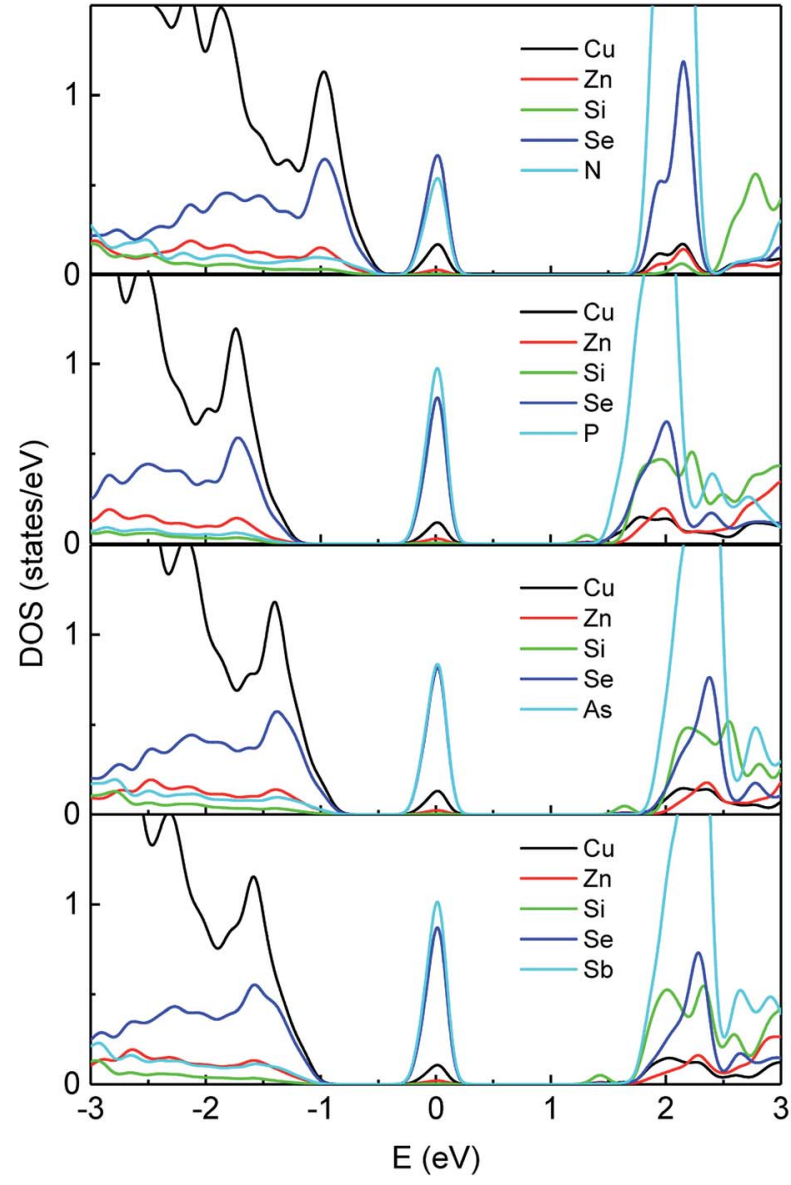

(b)

Fig. 3 (a) Total DOS and (b) PDOS of Cu, Zn, Si, Se and M (M = N, P, As, Sb) of group-VA doped $\mathrm{Cu}_{2} \mathrm{ZnSi}_{0.875} \mathrm{M}_{0.125} \mathrm{Se}_{4}$. (c) Partial charge density of the intermediate band (IB) of $\mathrm{Cu}_{2} \mathrm{ZnSi}_{0.875} \mathrm{P}_{0.125} \mathrm{Se}_{4}$. The iso-surface is plotted with 0.0015 e $\AA^{-3}$. The blue, grey, orange, green and cyan spheres represent $\mathrm{Cu}, \mathrm{Zn}, \mathrm{Si}, \mathrm{Se}$ and $\mathrm{P}$ atoms, respectively. 

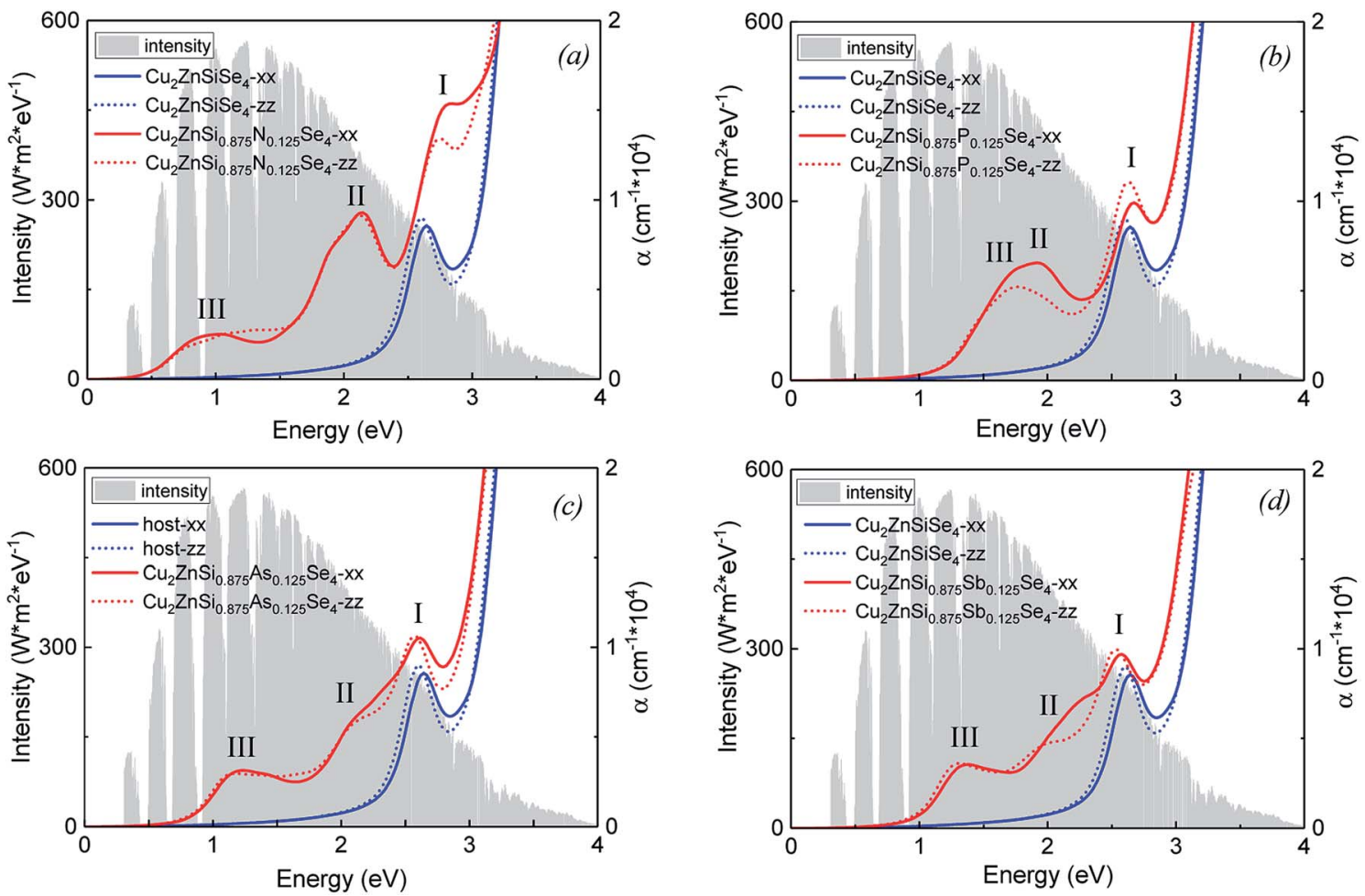

Fig. 4 The absorption coefficients of group-VA doped and host alloys. The solid and dotted lines represent the absorption coefficients parallel to the $a$-axis $\left(\alpha_{x x}\right)$ and $c$-axis $\left(\alpha_{z z}\right)$, respectively. The intensity of the solar light spectrum is also shown as a background. (a) $M=N$, (b) $M=P$, (c) $M=$ As, (d) $M=\mathrm{Sb}$. $M$ is the doped group-VA atom.

below $2.0 \mathrm{eV}$. It is noticed that there are three absorption peaks (labeled as I, II, and III, respectively, in Fig. 4) for each doped alloy. The peak I, caused by electron transition from VB to CB, slightly shifts to higher energy for the doping of $\mathrm{N}$ and $\mathrm{P}$ but shifts to lower energy for the doping of Sb. This is due to the bandgap between the VBM and CBM slightly increases for the doping of $\mathrm{N}$ and $\mathrm{P}$ and decreases for the doping of $\mathrm{Sb}$. The additional two peaks (II and III), caused by electron transitions from the IB to CB and from the VB to IB, locate at lower energy with more intensity of the solar light. Therefore, the absorption energy range is substantially broadened and the absorption coefficient is greatly enhanced due to dopant-introduced IBs. It is worth noticing that except $\mathrm{N}$-doped alloy, the sub bandgaps $\Delta_{2}$ IB-VBM of $\mathrm{P}$, As and Sb-doped alloys $(1.00,0.64$ and $0.80 \mathrm{eV}$, respectively) are very close to the optimal value $(0.92 \mathrm{eV})$, indicating that these doped alloys are promising candidates for the IBSC materials.

\section{Conclusions}

We have investigated electronic and optical properties of the group-VA (N, P, As, and Sb)-doped $\mathrm{Cu}_{2} \mathrm{ZnSiSe}_{4}$ alloys through hybrid functional calculations. The band structure predicted with an adjusted mixing parameter $\alpha(0.35)$ is more accurate than that through standard HSE06 functional. An isolated and partial filled IB is introduced by the doping of group-VA elements. IBs are formed dominantly by the anti-bonding hybridization of doped M-s states ( $\mathrm{M}=\mathrm{N}, \mathrm{P}, \mathrm{As}$ and $\mathrm{Sb})$ and
Se-4p states. For all of the four doped alloys, three absorption peaks can be clearly observed in the spectra and corresponding to the electron transitions from the $\mathrm{VB}$ to $\mathrm{CB}, \mathrm{IB}$ to $\mathrm{CB}$ and $\mathrm{VB}$ to IB, respectively. The absorption energy range is substantially broadened and the absorption coefficient is greatly enhanced. This result indicates that group-VA doped $\mathrm{Cu}_{2} \mathrm{ZnSiSe}_{4}$ alloys are promising intermediate band solar cell materials with high absorption efficiency for solar energy.

\section{Conflicts of interest}

There are no conflicts of interest to declare.

\section{Acknowledgements}

This work was supported by the National Natural Science Foundation of China under Grant Nos. 11674297, 11574289, U1632273 and Anhui Initiative in Quantum Information Technologies (AHY090300).

\section{References}

1 A. Luque and A. Martí, Increasing the efficiency of ideal solar cells by photon induced transitions at intermediate levels, Phys. Rev. Lett., 1997, 78, 5014-5017.

$2 \mathrm{~W}$. Shockley and H. Queisser, Detailed Balance Limit of Efficiency of p-n Junction Solar Cells, J. Appl. Phys., 1960, 1640, 510-519. 
3 A. Martí, E. Antolín, C. R. Stanley, C. D. Farmer, N. López, P. Díaz, E. Cánovas, P. G. Linares and A. Luque, Production of photocurrent due to intermediate-toconduction-band transitions: A demonstration of a key operating principle of the intermediate-band solar cell, Phys. Rev. Lett., 2006, 97, 247701.

4 S. Tomić, Intermediate-band solar cells: Influence of band formation on dynamical processes in InAs/GaAs quantum dot arrays, Phys. Rev. B: Condens. Matter Mater. Phys., 2010, 82, 195321.

5 A. Martí, D. F. Marrón and A. Luque, Evaluation of the efficiency potential of intermediate band solar cells based on thin-film chalcopyrite materials, J. Appl. Phys., 2008, 103, 073706.

6 T. Tanaka, M. Miyabara, Y. Nagao, K. Saito, Q. Guo, M. Nishio, K. M. Yu and W. Walukiewicz, Photocurrent induced by two-photon excitation in ZnTeO intermediate band solar cells, Appl. Phys. Lett., 2013, 102, 052111.

7 I. Aguilera, P. Palacios and P. Wahnón, Optical properties of chalcopyrite-type intermediate transition metal band materials from first principles, Thin Solid Films, 2008, 516, 7055.

8 M. Han, X. Zhang and Z. Zeng, The investigation of transition metal doped $\mathrm{CuGaS}_{2}$ for promising intermediate band materials, RSC Adv., 2014, 4, 62380-62386.

9 P. Palacios, I. Aguilera, K. Sánchez, J. C. Conesa and P. Wahnón, Transition-metal-substituted indium thiospinels as novel intermediate-band materials: prediction and understanding of their electronic properties, Phys. Rev. Lett., 2008, 101, 046403.

10 P. Chen, M. Qin, H. Chen, C. Yang, Y. Wang and F. Huang, $\mathrm{Cr}$ incorporation in $\mathrm{CuGaS}_{2}$ chalcopyrite: a new intermediate-band photovoltaic material with widespectrum solar absorption, Phys. Status Solidi A, 2013, 210, 1098.

11 I. Aguilera, P. Palacios and P. Wahnón, Enhancement of optical absorption in Ga-chalcopyrite-based intermediateband materials for high efficiency solar cells, Sol. Energy Mater. Sol. Cells, 2010, 94, 1903.

12 Ternary chalcopyrite semiconductors: growth electronic properties and applications, ed. J. L. Shay, J. H. Wernick and B. R. Pamplin, Pergamon Press, Oxford, New York, 1st edn, 1975, pp. 110-128.

13 X. Lv, S. Yang, M. Li, H. Li, J. Yi, M. Wang, G. Niu and J. Zhong, Investigation of a novel intermediate band photovoltaic material with wide spectrum solar absorption based on Ti-substituted $\mathrm{CuGaS}_{2}$, Sol. Energy, 2014, 103, 480-487.

14 B. Marsen, S. Klemz, T. Unold and H. W. Schock, Investigation of the sub-bandgap photoresponse in $\mathrm{CuGaS}_{2}$ : Fe for intermediate band solar cells, Prog. Photovolt. Res. Appl., 2012, 20, 625-629.

15 J. Hashemi, A. Akbari, S. Huotari and M. Hakala, Multiintermediate-band character of Ti-substituted $\mathrm{CuGaS}_{2}$ : implications for photovoltaic applications, Phys. Rev. B: Condens. Matter Mater. Phys., 2014, 90, 075154.
16 C. Yang, M. Qin, Y. Wang, D. Wan, F. Huang and J. Lin, Observation of an intermediate band in Sn-doped chalcopyrites with wide-spectrum solar response, Sci. Rep., 2013, 3, 1286.

17 X. Zhang, M. Han, Z. Zeng and Y. Duan, The role of Sb in solar cell material $\mathrm{Cu}_{2} \mathrm{ZnSnS}_{4}$, J. Mater. Chem. A., 2017, 5, 6606-6612.

18 D. Huang, J.-W. Jiang, J. Guo, Y.-J. Zhao, R. Chen and C. Persson, Group-IV ( $\mathrm{Si}, \mathrm{Ge}$, and $\mathrm{Sn}$ )-doped $\mathrm{AgAlTe}_{2}$ for intermediate band solar cell from first principles study, Semicond. Sci. Technol., 2017, 32, 065007.

19 M. Han, X. Zhang, Y. Zhang and Z. Zeng, The group VA element non-compensated n-p codoping in $\mathrm{CuGaS}_{2}$ for intermediate band materials, Sol. Energy Mater. Sol. Cells, 2016, 144, 664-670.

20 H. Matsushita, T. Ichikawa and a Katsui, Structural, thermodynamical and optical properties of $\mathrm{Cu}_{2}-\mathrm{II}-\mathrm{IV}-\mathrm{VI}_{4}$ quaternary compounds, J. Mater. Sci., 2005, 40, 2003-2005.

21 G. Kresse and J. Furthmüller, Efficiency of ab-initio total energy calculations for metals and semiconductors using a plane-wave basis set, Comput. Mater. Sci., 1996, 6, 15-50.

22 G. Kresse and J. Furthmüller, Efficient iterative schemes for ab initio total-energy calculations using a plane-wave basis set, Phys. Rev. B: Condens. Matter Mater. Phys., 1996, 54, 11169-11186.

23 P. E. Blochl, Projector augmentead-wave method, Phys. Rev. $B$, 1994, 50, 17953.

24 M. Jibran, Z. Y. Li, X. Sun, B. Wang, Y. Yamauchi and Z. J. Ding, Structural, electronic and optical properties of bandgap-tunable $\mathrm{Cu}_{2} \mathrm{ZnSi}_{\mathrm{x}} \mathrm{Sn}_{1-\mathrm{x}} \mathrm{Se}_{4}$ alloys, Chem. Phys. Lett., 2018, 705, 92-96.

25 A. P. Litvinchuk, V. M. Dzhagan, V. O. Yukhymchuk, M. Ya. Valakh, O. V. Parasyuk, L. V. Piskach, X. Wang, A. J. Jacobson and D. R. T. Zahn, Crystal structure and vibrational properties of $\mathrm{Cu}_{2} \mathrm{ZnSiSe}_{4}$ quaternary semiconductor, Phys. Status Solidi B, 2016, 253, 1808-1815.

26 M. Guc, S. Levcenko, V. Izquierdo-Roca, X. Fontane, M. Ya. Valakh, E. Arushanov and A. Pérez-Rodríguez, Polarized Raman scattering analysis of $\mathrm{Cu}_{2} \mathrm{ZnSiS}_{4}$ and $\mathrm{Cu}_{2} \mathrm{ZnSiSe}_{4}$ single crystals, J. Appl. Phys., 2013, 114, 173507.

27 M. Ya. Valakh, A. P. Litvinchuk, V. M. Dzhagan, V. O. Yukhymchuk, A. M. Yaremko, Yu. A. Romanyuk, M. Guc, I. V. Bodnar, A. Pérez-Rodríguez and D. R. T. Zahn, Fermi resonance in the phonon spectra of quaternary chalcogenides of the type $\mathrm{Cu}_{2} \mathrm{ZnGeS}_{4}, J$. Phys.: Condens. Matter, 2016, 28, 065401.

28 H. J. Monkhorst and J. D. Pack, Special points for Brillouinzone integrations, Phys. Rev. B: Solid State, 1976, 13, 51885192.

29 J. P. Perdew, K. Burke and M. Ernzerhof, Generalized gradient approximation made simple, Phys. Rev. Lett., 1996, 77, 3865-3868.

30 J. Heyd, G. E. Scuseria, M. Ernzerhof, J. Heyd, G. E. Scuseria and M. Ernzerhof, Hybrid functionals based on a screened Coulomb potential hybrid functionals based on a screened Coulomb potential, J. Chem. Phys., 2003, 118, 8207-8215. 
31 S. Kumar, D. K. Sharma and S. Auluck, Stability, electronic, and optical properties of wurtzite $\mathrm{Cu}_{2} \mathrm{Cd}_{\mathrm{x}} \mathrm{Zn}_{1-\mathrm{x}} \mathrm{SnS}_{4}$ alloys as photovoltaic materials: first-principles insight, Phys. Rev. $B, 2016$, 94, 235206-235216.

32 S. H. Wei and A. Zunger, Band offsets and optical bowings of chalcopyrites and Zn-based II-VI alloys, J. Appl. Phys., 1995, 78, 3846-3856.

33 Q. Shu, J. Yang, S. Chen, B. Huang, H. Xiang, X. Gong and S. Wei, $\mathrm{Cu}_{2} \mathrm{Zn}(\mathrm{Sn}, \mathrm{Ge}) \mathrm{Se}_{4}$ and $\mathrm{Cu}_{2} \mathrm{Zn}(\mathrm{Sn}, \mathrm{Si}) \mathrm{Se}_{4}$ alloys as photovoltaic materials: Structural and electronic properties, Phys. Rev. B: Condens. Matter Mater. Phys., 2013, 87, 115208.

34 S. Chen, A. Walsh, J.-H. Yang, X.-G. Gong, L. Sun, P.-X. Yang, J.-H. Chu and S.-H. Wei, Compositional dependence of structural and electronic properties of $\mathrm{Cu}_{2} \mathrm{ZnSn}(\mathrm{S}, \mathrm{Se})_{4}$ alloys for thin film solar cells, Phys. Rev. B: Condens. Matter Mater. Phys., 2011, 83, 125201. 